\title{
A Retrospective Evaluation of Patients with Operable Gastrointestinal Stromal Tumor
}

\section{Opere Gastrointestinal Stromal Tümörlü Hastaların Retrospektif Değerlendirmesi}

\author{
Efnan Algın ${ }^{1}$, Nuriye Özdemir ${ }^{1}$, Mutlu Doğan ${ }^{1}$, Gökmen Umut Erdem ${ }^{1}$, Doğan Uncu ${ }^{1}$, Tülay Keklik \\ Temuçin $^{2}$, Öznur Bal ${ }^{1}$, Nurullah Zengin ${ }^{1}$ \\ ${ }^{1}$ Ankara Numune Eğitim ve Araştırma Hastanesi, Tıbbi Onkoloji Kliniği, Ankara \\ ${ }^{2}$ Türkiye Yüksek İhtisas Eğitim ve Araştırma Hastanesi, Patoloji Kliniği, Ankara
}

Dergiye Ulaşma Tarihi: 13.03.2016 Dergiye Kabul Tarihi: 11.04.2016 Doi: 10.5505/aot.2016.93064

\section{ÖZET}

Amaç: Bu retrospektif çalışmada amacımız lokalize gastrointestinal stromal tümörlü (GİST) hastaların klinik ve histopatolojik özellikleri ile sağkalım oranlarını değerlendirmektir.

Yöntem: Nisan 2004 - Ekim 2014 tarihleri arasında Ankara Numune Eğitim ve Araştırma Hastanesi Tıbbi Onkoloji Kliniği'ne başvuran GIST tanılı 94 hasta arasından opere olmuş ve tanı sırasında metastazı olmayan 65 hastanın dosya bilgileri kaydedildi.

Bulgular: Çalışmaya alınan 65 hastanın ortanca yaşı 53 (22-78) olup; çoğunluğu erkekti (erkek/kadın: 41/24). Tümörlerin yerleşim yeri sıklık sırasına göre mide (\%58.5), mide dişı gastrointestinal $(\% 29.2)$, ve ekstragastrointestinal (\%12.3) olarak belirlendi. AFIP'e göre hastaların \%24.6's1 düşük, \%21.5'i orta ve \%53.9'u yüksek risk grubunda yer alırken; sadece \%33.8'i adjuvan imatinib tedavisi aldı. Tüm grupta ortanca genel sağkalıma ulaşılamazken; 3 yıllık hastalıksız sağkalım (DFS) \%81, 2 yıllık DFS ise \%84 olarak belirlendi. Cinsiyet, tümörün lokalizasyonu, tümör çapı, mitoz sayısı, CD34, AFIP risk grubu ve adjuvan tedavi alıp almama durumuna göre hem 2 hem de 3 yıllık DFS'de istatistiksel anlamlılığa ulaşan fark saptanmadı.

Sonuç: Tanı sırasında lokalize olup cerrahi tedavi yapılan GIST olgularında ortanca sağkalıma ulaşılamazken; DFS oranları yüksek bulunmuştur.

Anahtar kelimeler: Gastrointestinal stromal tümör, imatinib, CD117, hastalıksız sağkalım

\begin{abstract}
Aim: In this retrospective study, we aimed to evaluate the clinical and histopathological features and survival rates of patients with localized gastrointestinal stromal tumors (GIST).

Method: Between April 2004 and October 2014, 94 patients diagnosed with GIST who were referred to the Department of Medical Oncology, Ankara Numune Education and Research Hospital were retrospectively reviewed. A total of 65 nonmetastatic operable GIST patients were included in the study.

Results: The median age was 53 years (22-78) and most patients were male (male/female: 41/24). The most common localization of tumors were stomach (58.5\%), non-gastric gastrointestinal (29.2\%), and ekstragastrointestinal (12.3\%). According to the AFIP prognostic criteria, 24.6\% of patients was located in low risk group, $21.5 \%$ in intermediate risk group, and $53.9 \%$ in high risk group. Only $33.8 \%$ of patients received adjuvant imatinib treatment. While the median overall survival (OS) was not reached, 3 year and 2 year disease free survival (DFS) was $81 \%$ and $84 \%$ respectively. There was no statistically significant difference neither in 2 year DFS nor in 3 year DFS according to gender, tumor site, tumor size, mitotic count, CD34, AFIP risk group and adjuvant treatment.

Conclusion: The median OS was not reached in localized GIST patients who underwent surgery, whereas a high DFS rate was found.
\end{abstract}

Keywords: Gastrointestinal stromal tumor, imatinib, CD117, disease free survival

\section{Giriş}

Gastrointestinal stromal tümörler (GIST), gastrointestinal (GI) sistemin en s1k görülen mezenkimal tümörleridir $(1,2)$. Geçmişte bu tümörler leyomyom, leyomyosarkom veya leyomyoblastom olarak siniflandirilırken; elektron mikroskobu ve immünohistokimyasal yöntemlerin keşfi ile birlikte ayrı bir tümör grubu olarak değerlendirilmeye başlanmıştır (3-4). Sporadik GIST vakalarının yaklaşık \%70-80'inde KIT geninde sonradan kazanılmış fonksiyonel mutasyonlar saptanırken; \%5-10 vakada PDGFR $\alpha$ aktivasyonuna yol açan mutasyonlar mevcuttur. Vakaların \%1015'inde ise bu mutasyonların hiçbirine rastlanmaz (5-6).

Gastrointestinal stromal tümörler Gİ sistemin her yerinde gelişebilse de, en sik midede 
görülmektedir. Nadiren; Gİ sistem dişında mezenter, omentum ve retroperitonda da gelişebilmektedir (7). Lokalize hastalıkta küratif tedavi yöntemi cerrahi rezeksiyondur. Cerrahi tedavinin primer amac1 tümörsüz cerrahi sınır (R0) elde edecek şekilde kitleyi çıkarabilmektir (8). Ancak R0 rezeksiyonun yapılabildiği hastaların bile yaklaşık yarısında 5 yıl içinde nüks veya metastaz gelişmektedir (9). Primer tümörü tamamen çıkarılmış GIST vakalarında nüks riski; tümör çapı, yerleşim yeri ve mitoz sayısını içeren "the Armed Forces Institute of Pathology (AFIP)" prognostik kriterleri doğrultusunda belirlenmektedir (10). Yüksek riskli hastalarda cerrahi rezeksiyon sonrasi adjuvan imatinib tedavisi ile nükssüz sağkalım belirgin olarak uzamaktadır (11).

$\mathrm{Bu}$ araştırmada amacımız; kliniğimizde erken evre GIST tanısı almış olan olguların demografik özelliklerini, histopatolojik bulgularını, uygulanan tedavi yöntemleri ile sonuçlarını incelenmektir.

\section{Yöntem:}

Nisan 2004 - Ekim 2014 tarihleri arasında Ankara Numune Eğitim ve Araştırma Hastanesi Tibbi Onkoloji Kliniği'ne başvuran, 18-90 yaş aras1, GİST tanılı 94 hastanın dosyalar1 retrospektif olarak incelendi. Bunlar arasindan tanı sirasinda metastazı olan 29 hasta çalışma dışı bırakıldı. Tanı konduğu sırada metastazı olmayıp opere edildiği belirlenen 65 hastanın demografik özellikleri, tedavi yöntemleri, postoperatif histopatolojik bulguları ve tedavi sonuçları kaydedildi. Sağkalım ve nüks oranları araştırıldı. Tüm istatistiksel analizler, bilgisayar ortamında, SPSS 20.00 paket programı kullanılarak yapıldı. Sağkalım oranlarını hesaplamak için Kaplan-Meier testi kullanıldı. Genel sağkalım (OS), histopatolojik olarak tanı konulduğu tarihten itibaren herhangi bir nedene bağl1 olarak görülen ölüme kadar geçen süre olarak tanımlandı. Hastalıksız sağkalım (DFS) ise, primer tedavi yöntemi olan cerrahi tarihinden itibaren nükse kadar geçen süre olarak tanımlandı. $\mathrm{P}$ değerinin 0.05 'ten küçük olması istatistiksel olarak anlamlı kabul edildi.

\section{Sonuçlar:}

Tanı konduğu sırada metastazı olmayan GíST tanılı 65 hasta çalıșmaya alındı. Hastaların ortanca yaş1 53 (22-78) olup; 41'i erkek, 24'ü kadındı. İki hasta, tanı sırasında lokal ileri hastalığı olması nedeniyle, neoadjuvan imatinib tedavisi sonrasi opere edildi. Tümörlerin yerleşim yeri sıklık sırasına göre mide (\%58.5), mide dış1 gastrointestinal (\%29.2), ve ekstragastrointestinal (\%12.3) olarak belirlendi. Uygulanan cerrahi tedavi yöntemleri Tablo 1'de sunuldu.

Tablo 1. Uygulanan cerrahi tedavi yöntemleri

\begin{tabular}{lcc}
\hline Cerrahi Yöntem & $\begin{array}{c}\text { Hasta sayısı } \\
(\mathbf{n = 6 5 )}\end{array}$ & $\mathbf{\%}$ \\
\hline \hline Total gastrektomi & 4 & 6,2 \\
Parsiyel gastrektomi & 14 & 21,5 \\
Gastrik kitle rezeksiyonu & 20 & 30,8 \\
Parsiyel ince barsak rezeksiyonu & 17 & 26,1 \\
Parsiyel kolon rezeksiyonu & 2 & 3,1 \\
Retroperitoneal kitle rezeksiyonu & 8 & 12,3 \\
\hline
\end{tabular}

Postoperatif histopatolojik inceleme sonucunda vakaların \%50'sinde mitoz sayıs1 50 büyük büyütme alanında 5'in altında, \%23.4'ünde 510 arasında, \%26.6'sinda ise 10'un üzerinde bulundu. Tümör çap1 $2 \mathrm{~cm}$ ve altında olan hastalarin oranı $\% 1.5,2.1-5 \mathrm{~cm}$ arasinda olanlar \%21.5, 5.1-10 $\mathrm{cm}$ arasindakiler \%47.7, $10 \mathrm{~cm}$ 'nin üzerinde olanlar ise $\% 29.3$ olarak hesapland1. CD117 negatif olan sadece 3 hasta olmakla birlikte; hastaların \%34'ünde CD34 negatif olarak saptandi. Üç hastada cerrahi sırasında rüptür gelişti. Vakaların \%86.2' sinde R0，\%7.7'sinde R1，\% 7.1'inde ise R2 rezeksiyon yapılmış olduğu görüldü. AFIP kriterlerine göre hastaların 16'sının düşük $(\% 24.6)$, 14'ünün orta $(\% 21.5)$ ve 35 'inin (\%53.9) yüksek risk grubunda yer aldığ 1 belirlendi.

Adjuvan tedavi durumları incelendiğinde; tüm grupta sadece 22 hastanın (\%33.8) adjuvan imatinib tedavisi aldığ 1 görüldü. Bu hastaların 19'u yüksek risk grubunda yer alırken, 3 hasta orta risk grubundaydı. Yüksek risk grubundaki hastalar ayrıntılı olarak değerlendirildiğinde ise sadece \%54.3'ünün adjuvan tedavi aldığ saptand1.

Adjuvan tedavi alan 22 hastanın 3'ünde (\%13.6) lokal veya uzak nüks gelişirken, adjuvan tedavi almayan 43 hastanın 13'ünde (\%30) nüks olduğu görüldü. İki grup arasındaki fark istatistiksel olarak anlaml değildi $(\mathrm{p}=0.14)$. 
Tüm grupta ortanca sağkalıma ulaşılamamakla birlikte; 3 yıllık hastalıksız sağkalım (DFS) $\% 81,2$ y1llık DFS ise \%84 olarak belirlendi. Cinsiyet, tümörün lokalizasyonu, tümör çapı, mitoz say1s1, CD34, AFIP risk grubu ve adjuvan tedavi alıp almama durumuna göre hem 2 hem de 3 ylllik DFS'de istatistiksel anlamlılığa ulaşan fark saptanmadı (Tablo 2).

Tablo 2. Opere GIST hastalarında klinik ve

\begin{tabular}{|c|c|c|c|}
\hline & $\begin{array}{c}2 \text { Yillık } \\
\text { DFS }(\%) \\
\end{array}$ & $\begin{array}{c}3 \text { Yillık } \\
\text { DFS }(\%) \\
\end{array}$ & $p$ değeri \\
\hline Cinsiyet & & & 0.11 \\
\hline Erkek & 75 & 75 & \\
\hline Kadın & 90 & 90 & \\
\hline Tümör çapı & & & 0.13 \\
\hline$\leq 2 \mathrm{~cm}$ & 100 & 100 & \\
\hline $2.1-5 \mathrm{~cm}$ & 92 & 92 & \\
\hline $5.1-10 \mathrm{~cm}$ & 87 & 87 & \\
\hline$>10 \mathrm{~cm}$ & 70 & 63 & \\
\hline Mitoz sayısı & & & 0.07 \\
\hline$<5 / 50 \mathrm{BBA}$ & 93 & 89 & \\
\hline 5-10/50 BBA & 87 & 87 & \\
\hline$>10 / 50 \mathrm{BBA}$ & 63 & 63 & \\
\hline Lokalizasyon & & & 0.14 \\
\hline Gastrik & 85 & 85 & \\
\hline Ekstragastrik & 88 & 82 & \\
\hline Ekstragastrointestinal & 66 & 66 & \\
\hline AFIP risk grubu & & & 0.32 \\
\hline Düşük risk & 79 & 70 & \\
\hline Orta risk & 92 & 92 & \\
\hline Yüksek risk & 92 & 92 & \\
\hline CD34 & & & 0.27 \\
\hline Negatif & 79 & 73 & \\
\hline Pozitif & 91 & 87 & \\
\hline Adjuvan imatinib & & & 0.36 \\
\hline Evet & 95 & 87 & \\
\hline Hayır & 82 & 79 & \\
\hline
\end{tabular}

histopatolojik özelliklere göre 2 ve 3 yıllık DFS oranları

\section{Tartışma:}

Gastrointestinal stromal tümörler her yaşta görülebilmekle birlikte; tanı sirasında hastaların çoğu 40 ile 80 yaş arasındadır. Farklı seriler incelendiğinde; bildirilen ortanca yaşın 55 ile 65 arasında değiştiği görülmektedir. Bazı serilerde cinsiyet dağılımının eşit olduğu rapor edilirken, bazılarında ise erkeklerde daha s1k görüldüğü bildirilmektedir (12-15). Bizim çalışmamızda ortanca yaş 53 olarak Adress for correspondence: Uzm. Dr. Efnan Algın, Ankara Numune Eğitim ve Araştırma Hastanesi, Tıbbi Onkoloji Kliniği, Sihhiye/ Ankara - Türkiye e-mail: efnanalgin@gmail.com

Available at www.actaoncologicaturcica.com

Copyright $\odot$ Ankara Onkoloji Hastanesi belirlenmiş olup; hastalarımızın çoğu erkekti (E/K : 41/24).

Gastrointestinal stromal tümörler en s1k midede (\%60-70), daha sonra sirasiyla ince barsak (\%20-30), duedonum (\%4-5), rektum (\%4-5), kolon (\%2) ve özefagusta $(<\% 1)$ görülmektedir. Nadiren; Gİ sistem dışında mezenter, omentum ve retroperitonda da gelişebilmektedir $(10,17)$. Bizim çalışmamızda da en sik yerleșim yeri literatür ile benzer şekilde mide $(\% 58.5)$ olarak tespit edildi. $\% 29.2$ oranındaki ekstragastrik GIST vakalarımız ince barsak (\%26.1) ve kolondan (\%3.1) kaynaklaniyordu.

Rezeke edilebilir GIST vakalarında primer tedavi yöntemi cerrahidir. $\mathrm{Bu}$ vakalarda $\mathrm{R} 0$ rezeksiyon oranı literatürde $\% 85$ olarak belirtilmiştir (9). Bizim hastalarımızda da R0 rezeksiyon oran $1 \% 86.2$ olup literatür ile uyumludur. Operasyonun morbiditesini azaltmak ve R0 rezeksiyona olanak sağlamak adına; tirozin kinaz inhibitörleri ile neoadjuvan tedaviler gündemdedir (18). Bazı yazarlar tarafından, neoadjuvan imatinib tedavisi ile primer tümörde median \%34'lük küçülme olduğu bildirilmekle birlikte tedavinin süresi henüz netlik kazanmamıştır (19). Eisenberg ve arkadaşları, yanıt değerlendirmesinin erken ve düzenli olarak yapılması gerektiğini ve olumlu yanıt alınması halinde 3-6 ay içinde opere edilmesi gerektiğini bildirmişlerdir (20). Bizim hastalarımız arasından da iki tanesine 3 ve 12 ay süreyle neoadjuvan imatinib tedavisi uygulanmış ve sonuçta R0 rezeksiyon yapılabilmiştir.

R0 rezeksiyon yapılan GIST vakalarının bile yaklaşık yarısında 5 yıl içinde nüks veya metastaz geliştiği bilinmektedir (9). GIST, kemoterapi ve radyoterapiye karşı duyarlı değildir. Metastatik GIST vakalarının imatinib ile başarılı biçimde tedavi edilmesi; araştırmacıları, adjuvan imatinib tedavisinin faydalı olup olmadığını araştırmaya yöneltmiştir. 2008'de yayınlanan, faz 3, çift kör, plasebo kontrollü, çok merkezli çalışma sonucunda; yüksek riskli hastalarda 1 yıl süreyle uygulanan adjuvan imatinib tedavisi ile nükssüz sağkalımın belirgin olarak uzadığ1 gösterilmiştir (10). 2012'de ise Joensuu ve arkadaşlarının yürüttüğü randomize açık etiketli çalışmanın sonuçları yayınlanmış ve yüksek riskli hastalarda 1 yıla karşın 3 y1l süreyle uygulanan adjuvan imatinib tedavisinin, hem nükssüz sağkalımı hem de 
genel sağkalımı uzattığı saptanmıştır (21). Bizim çalışmamızda yüksek risk grubundaki hastalar incelendiğinde, sadece \%54.3'ünün adjuvan tedavi aldığı saptandı. Yüksek riskli grupta yer almasına rağmen her hastaya adjuvan tedavi verilmeme nedenini araştırdığımızda; adjuvan tedavi alan hastalarımızın 2009 yilı ve sonrasinda tan aldığını gördük. Buradan yola çıkarak düşük tedavi oranımızın; hastalarımıza tanı konduğu tarihte, henüz adjuvan tedavinin gündemde olmamasından kaynaklandığı kanısına vardık. Lokalize hastalıkta küratif tedavi yöntemi cerrahi rezeksiyon olmakla birlikte; R0 rezeksiyonun yapılabildiği hastaların bile $\% 50$ 'sinde 5 y1l içinde nüks veya metastaz gelişmekte ve 5 yıllık sağkalım oranlarının \%50 civarında olduğu bildirilmektedir (9). Yüksek riskli hastalarda cerrahi rezeksiyon sonras1 adjuvan imatinib tedavisi ile DFS belirgin olarak uzamaktadır (11). DeMatteo ve arkadaşları, adjuvan imatinib tedavisi alan yüksek riskli hastalarda 1,3 ve 5 yıllık DFS

\section{Kaynaklar:}

1. Goettsch WG, Bos SD, Breekveldt-Postma N, Casparie M, Herings RM, Hogendoorn PC. Incidence of gastrointestinal stromal tumours is underestimated: results of a nation-wide study. Eur J Cancer. 2005;41:2868-72.

2. Reddy P, Boci K, Charbonneau C. The epidemiologic, healthrelated quality of life, and economic burden of gastrointestinal stromal tumours. J Clin Pharm Ther. 2007;32:557-65.

3. Walker P, Dvorak AM. Gastrointestinal autonomic nevre (GAN) tumor. Ultrastructural evidence for a newly recognized entity. Arch Pathol Lab Med. 1986; 110(4):309-16.

4. Mazur MT, Clark HB. Gastric stromal tumors. Reappraisal of histogenesis. Am J Surg Pathol. 1983; 7(6):507-19.

5. Corless CL, Barnett CM, Heinrich MC. Gastrointestinal stromal tumours: origin and molecular oncology. Nat Rev Cancer. 2011;11:86578.

6. Demetri GD, von Mehren M, Antonescu CR, et al. NCCN Task Force report: update on the management of patients with gastrointestinal stromal tumors. J Natl Compr Canc Netw. 2010;8 (suppl 2):1-41.

7. Appelman HD. Mesenchymal tumors of the gut: historical perspectives, new approaches, new results, and does it make any difference? Monogr Pathol. 1990;31:220-46.

8. Pierie JP, Choudry U, Muzikansky A, Yeap BY, Souba WW, Ott MJ. The effect of surgery and grade on outcome of gastrointestinal stromal tumors. Arch Surg. 2001;136:383-9. oranlarını sirasiyla $\% 96, \% 60$ ve $\% 40$ olarak bildirilmiştir (22). Bizim çalışmamızda ortanca sağkalıma ulaşılamazken; 2 ve 3 yıllık DFS oranları sirasiyla $\% 81$ ve $\% 84$ olarak bulundu. Sağkalım oranlarımızın literatüre göre daha yüksek olduğu görülmekle birlikte; bu farkın nedeni, hasta popülasyonumuzun risk grubu açısından homojen olmaması olabilir (\%24.6 düşük riskli, \%21.5 orta riskli, \%53.9 yüksek riskli).

Sonuç olarak; GİST gastrointestinal sistemin en s1k görülen mezenkimal tümörü olup, en s1k mideden kaynaklanmaktadır. Lokalize hastalıkta önerilen tedavi yöntemi cerrahi rezeksiyon olsa da, her zaman tek başına kür sağlayamamaktadır. Primer tümörün tam olarak rezeke edilebildiği vakalarda bile nüks oranı yüksektir. Yüksek riskli hastalarda adjuvan imatinib tedavisi ile sağkalım belirgin olarak uzamıştır. Adjuvan tedaviden fayda görecek yüksek riskli hastaların tespit edilmesinde histopatolojik incelemenin önemi büyüktür.

9. DeMatteo RP, Lewis JJ, Leung D, Mudan SS, Woodruff JM, Brennan MF. Two hundred gastrointestinal stromal tumors: recurrence patterns and prognostic factors for survival. Ann Surg. 2000;231:51-8.

10. Miettinen M, Lasota J. Gastrointestinal stromal tumors: pathology and prognosis at different sites. Semin Diagn Pathol. 2006;23:70-83.

11. Dematteo RP, Ballman KV, Antonescu CR, et al. American College of Surgeons Oncology Group (ACOSOG) Intergroup Adjuvant GIST Study Team. Adjuvant imatinib mesylate after resection of localised, primary gastrointestinal stromal tumour: a randomised, doubleblind, placebo-controlled trial. Lancet. 2009;373:1097-104.

12. Miettinen M, Sobin LH, Sarlomo-Rikala M. Immunohistochemical spectrum of GISTs at different sites and their differential diagnosis with a reference to CD117 (KIT). Mod Pathol. 2000;13:1134-42.

13. Miettinen M, Sarlomo-Rikala M, Lasota J. Gastrointestinal stromal tumors: recent advances in understanding of their biology. Hum Pathol. 1999;30:1213-20.

14. Ueyama T, Guo KJ, Hashimoto H, Daimaru Y, Enjoji M. A clinicopathologic and immunohistochemical study of gastrointestinal stromal tumors. Cancer. 1992;69:947-55.

15. Lerma E, Oliva E, Tugues D, Prat J. Stromal tumours of the gastrointestinal tract: a clinicopathological and ploidy analysis of 33 cases. Virchows Arch. 1994;424:19-24.

16. Machado-Aranda D, Malamet M, Chang YJ, et al. Prevalence and management of gastrointestinal stromal tumors. Am Surg. 2009;75:55-60. 
17. Monges G, Bisot-Locard S, Blay JY, et al. The estimated incidence of gastrointestinal stromal tumors in France. Results of PROGIST study conducted among pathologists. Bull Cancer. 2010;97:16-22.

18. Lopes LF, Bacchi CE. Imatinib treatment for gastrointestinal stromal tumour (GIST). J Cell Mol Med. 2010;14:42-50.

19. Fiore M, Palassini E, Fumagalli E, et al. Preoperative imatinib mesylate for unresectable or locally advanced primary gastrointestinal stromal tumors (GIST). Eur J Surg Oncol. 2009; 35:739-45.

20. Eisenberg BL, Smith KD. Adjuvant and neoadjuvant therapy for primary GIST. Cancer Chemother Pharmacol. 2011;67 (Suppl 1):3-8.

21. Joensuu H, Eriksson M, Sundby Hall K, et al. One vs three years of adjuvant imatinib for operable gastrointestinal stromal tumor: a randomized trial. JAMA. 2012;307:1265-72.

22. Ronald P. DeMatteo, Karla V. Ballman, Cristina R. Antonescu, et al. Long-term results of adjuvant imatinib mesylate in localized, high-risk, primary gastrointestinal stromal tumor (GIST): ACOSOG Z9000 (Alliance) intergroup phase 2 trial. Ann Surg. 2013;258:422-9. 